\title{
SUITABILITY OF PHENYLALANINE AMMONIA LYASE AND CHITINASE ACTIVITIES AS BIOCHEMICAL MARKERS OF SOFT ROT RESISTANCE IN ACTINIDIA CHINENSIS KIWIFRUIT
}

\author{
K.V. WURMS, A. AH CHEE, T. REGLINSKI and J.T. TAYLOR \\ HortResearch, Ruakura Research Centre, Private Bag 3123, Hamilton, \\ New Zealand \\ Correspondingauthor: kwurms@hortresearch.co.nz
}

\begin{abstract}
Cryptosporiopsis actinidiae causes soft rot of the kiwifruit cultivar Hort16A (Actinidia chinensis). This paper describes measurement of phenylalanine ammonia lyase (PAL) and chitinase, with a view to identifying possible resistance markers to characterise the host/pathogen interaction. Four A. chinensis genotypes were treated pre-harvest with water or $C$. actinidiae spores. Fruit was stored at $1.5^{\circ} \mathrm{C}$ for 18 weeks to allow for disease development. Enzyme activities were measured at harvest and after storage in the area around disease lesions and in symptomless tissue. Soft rot incidence was highest in genotype 8A and equal in the other genotypes. Pre-harvest inoculation had no effect on subsequent soft rot incidence. Chitinase activities varied with genotype, and increased significantly during storage, but there was no difference between healthy versus diseased tissue. PAL expression varied with genotype, increased during storage, and was always significantly higher in the tissue around lesions. Neither enzyme measurement was a suitable resistance marker. Keywords: Cryptosporiopsis, chitinase, Hort16A, phenylalanine ammonia lyase (PAL), resistance, soft rots.
\end{abstract}

\section{INTRODUCTION}

ZESPRI International Limited, together with the breeders at HortResearch, New Zealand, are constantly looking to maintain New Zealand's competitive edge in the global market by the introduction of novel kiwifruit. When developing future commercial Actinidia varieties, genotypes must have a level of susceptibility to pests and diseases that does not exceed that of current commercial varieties. Ideally, new varieties should also be capable of being produced organically. Past research indicates that there is a significant amount of variation in susceptibility between Actinidia species to both pests and diseases (Reglinski et al. 2001; Wurms 2004; Hill et al. 2007; McKenna et al. 2006). Simple tools capable of measuring the relative or absolute levels of resistance of Actinidia germplasm samples to a specific pest or disease are required, to enable the requisite level of resistance to be built into future breeding and progeny screening programmes.

Cryptosporiopsis actinidiae is one of the major causal agents of soft rots, which are the main postharvest disease problem of Hort16A fruit (Manning et al. 2003). Infection occurs predominantly during flowering, with the pathogen residing in the fruit surface in a latent state until $12+$ weeks of cold storage, when soft rot disease symptoms start to develop (Rheinländer et al. 2005). Soft rots are characterised by small sunken circular pits with defined margins, found anywhere on the fruit surface (Manning et al. 2003).

Two enzymes, chitinase and phenylalanine ammonia lyase (PAL), have been correlated with resistance of commercial kiwifruit varieties to Botrytis cinerea (Wurms 2005) and Sclerotinia sclerotiorum (Reglinski et al. 2001). Assays for these enzymes are reliable and affordable, so the aim of this study was to determine if they could be 
used as selection tools to screen for resistance of Actinidia chinensis cv. Hort16A to Cryptosporiopsis actinidiae, since virtually nothing is known about resistance in this host/pathogen interaction.

\section{METHODS}

The four genotypes studied in this trial were Hort16A and three other mature A. chinensis genotypes (4C, 8A and 10B). These were selected on the basis of a similar flowering time to Hort16A, so that the stage of physiological development would be similar in each genotype at the time of inoculation. Genotypes 4C, 8A and 10B were produced by crosses of three different female A. chinensis parents, one of which was Hort16A, with 3 different male A. chinensis parents. Based on previous studies that determined the optimal inoculation time (Rheinländer et al. 2005; Fullerton et al. 2007), flowers/fruitlets of the four $A$. chinensis genotypes were spray-inoculated with a freshly prepared spore suspension (1.3-4.0 × $10^{6}$ spores $/ \mathrm{ml}$ of $0.01 \%$ Triton $\left.{ }^{\circledR}\right)$ of C. actinidiae, and controls with $0.01 \%$ Triton on four occasions between blossom time (late October) and the green fruitlet stage (late January). Spore suspensions were prepared by flooding 2-week-old cultures of $C$. actinidiae on potato dextrose agar (PDA) with $0.01 \%$ Triton and adjusting final spore counts using a haemocytometer. There were 4 replicate vines, with alternate canes on the vine designated as inoculated or control treatments.

Inoculated and control fruit for biochemical analyses were sampled at harvest (early May) and after 18 weeks at $1.5^{\circ} \mathrm{C}$ in air. Soft rot incidence was recorded after 18 weeks of cold storage by counting the number of fruit in each tray with sunken pits and expressing this as a percentage of fruit infected per tray. There were four trays for each treatment at each sampling time.

Crude extracts for assessment of chitinase activity were prepared by homogenising fruit skin tissue in $0.1 \mathrm{M}$ sodium acetate buffer $(\mathrm{pH}$ 5.6) at a 1:3 weight:volume ratio (Wurms et al. 1997). Each extract was produced from 3-5 pooled fruits per tray, with four trays per treatment. Only symptomless tissue was sampled to minimise the extraction of fungal enzymes (Wurms et al. 1997). At harvest there were no disease symptoms, so all extracts came from healthy tissue. After storage, tissue for the "diseased" extracts, was sampled from the zone of symptomless tissue immediately surrounding sunken pits (the most definitive symptom of infection by C. actinidiae), whilst "healthy" tissue was sampled either from uninfected fruits in the same tray, or in the case where all fruit within a tray were infected, from areas on the fruit that were clear of pits. Sampling healthy tissue after storage was difficult in genotype 4C since fruit tissue had softened to the point of collapse, most probably because of chilling injury, and was extensively colonised by opportunistic secondary pathogens. Chitinase activity was measured as the release of radio-labelled $\mathrm{N}$-acetyl glucosamine fragments from tritiated chitin using the radioassay of Molano et al. (1977), with modifications as described by Wurms et al. (1997), except that 30-60 $\mu \mathrm{l}$ of test extract and $35 \mu \mathrm{l}$ of tritiated chitin substrate were used. Radioactivity was measured in $3 \mathrm{ml}$ of BCS scintillant (Amersham Corporation, Arlington Heights, IL, United States) on a 1218 Rackbeta scintillation counter (LKB Wallac, Wallac Oy, Finland).

Fruit skin samples for measurement of phenylalanine ammonia-lyase (PAL) were extracted for $2 \mathrm{~h}$ in $0.5 \mathrm{M}$ potassium phosphate buffer $(\mathrm{pH} 7.5)$ containing $0.2 \mathrm{M}$ ascorbic acid, $1.5 \%$ polyethylene glycol, $50 \mathrm{mM}$ cysteine, $5 \mathrm{mM}$ EDTA and $0.4 \mathrm{M}$ sucrose. Immediately before measurement of enzyme activity, crude extracts were mixed with $20 \mathrm{mg}$ of polyclar AT for $15 \mathrm{~min}$, then cleared by centrifugation and passed through a protein desalting spin column (Pierce Biotechnology, Inc. USA). PAL activity was measured using L- $\left[\mathrm{U}-{ }^{14} \mathrm{C}\right]$ phenylalanine (Amersham) as described by Bernards \& Ellis (1989).

The experiment had a nested design with "disease status" nested within "inoculation treatment" and "inoculation treatment" nested within "A. chinensis selection". There were four trays, each containing ca 25 fruit per treatment. Rot incidence, chitinase and PAL enzyme activities were all analysed separately, but the nested design was applied 
in each case. Analysis of variance (ANOVA) and standard error of the mean (SEM) calculations were performed using SAS software, version 9.1 (SAS Institute, Cary, North Carolina, United States), with data transformation ( $\log _{\mathrm{e}}$ or a square root transformation) when necessary. However, ANOVA statistics applied only to the main treatment effects (cultivar type), since comparisons of the interactions between disease status, inoculum treatments and $A$. chinensis selection on rot incidence, chitinase and PAL enzymes were not possible, because of the hierarchical nature of the nested design.

\section{RESULTS}

Overall, the incidence of soft rots was significantly greater in genotype $8 \mathrm{~A}(\mathrm{P}=0.0008)$ than in all other A. chinensis selections. However, it was difficult to distinguish soft rots from other secondary rots in genotype $4 \mathrm{C}$, because chilling injury, and subsequent tissue breakdown and colonisation by other microbes was so extensive. Figure 1 shows that regardless of $A$. chinensis genotype, there were no major differences in percentage rots between control and inoculated fruits.

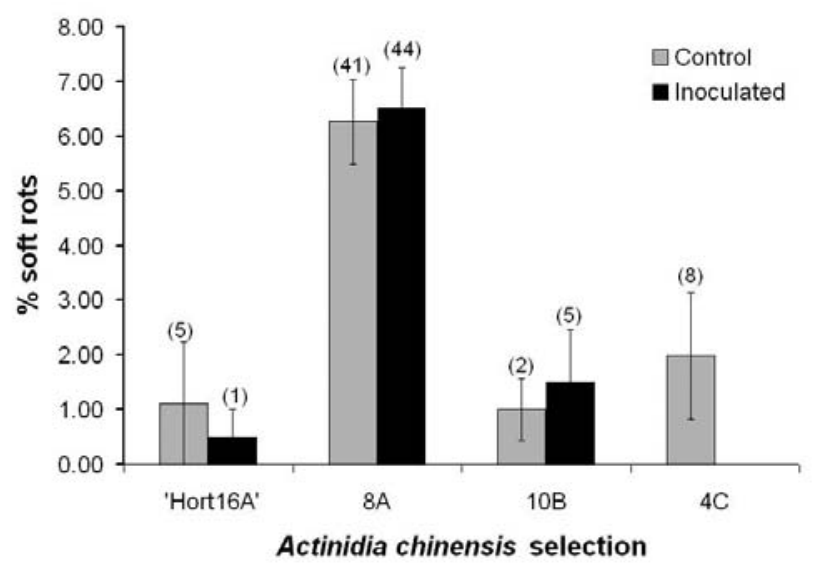

FIGURE 1: Soft rot (caused by Crytosporiopsis actinidae) incidence in four Actinidia chinensis selections, Hort16A, 8A, 10B and 4C. Disease incidence, expressed as percentage of soft rots in trays of fruit that had been inoculated pre-harvest with Cryptosporiopsis actinidiae or treated with water (control fruit), was assessed after 18 weeks of storage at $1.5^{\circ} \mathrm{C}$. Data are presented after square root transformation, with error bars indicating SEM, and untransformed means in parentheses.

Chitinase activity differed significantly between the $A$. chinensis selections $(\mathrm{P}=0.005)$, with greatest activity in genotype $10 \mathrm{~B}$ and Hort $16 \mathrm{~A}$, followed by genotype $4 \mathrm{C}$, and markedly less activity in genotype 8A. Figure 2 illustrates that chitinase activity increased markedly during cold storage relative to harvest in all selections, but that there were no significant or consistent differences between healthy (non-infected) and diseased (infected) tissue and no effect of the inoculation treatment. 

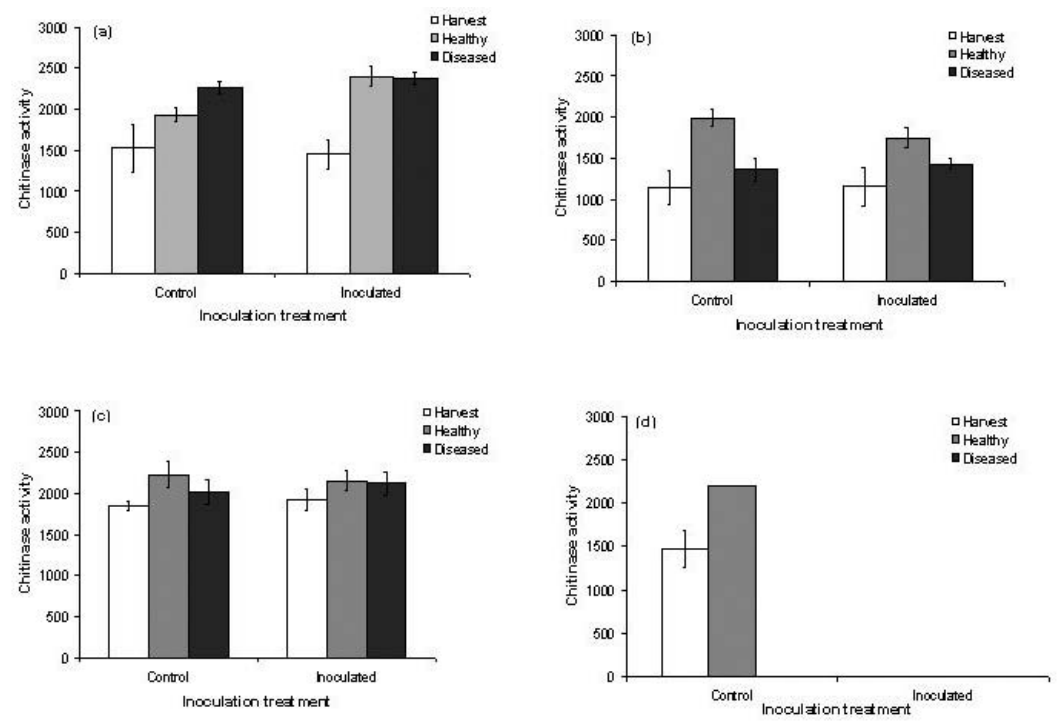

FIGURE 2: Chitinase activity in four Actinidia chinensis selections, (a) Hort16A, (b) genotype $8 \mathrm{~A}$, (c) genotype $10 \mathrm{~B}$ and (d) genotype $4 \mathrm{C}$, as measured at harvest time, and after 18 weeks of storage at $1.5^{\circ} \mathrm{C}$ in healthy and diseased kiwifruit fruit tissue that had been inoculated pre-harvest with Cryptosporiopsis actinidiae or treated with water (control fruit). Chitinase activity is expressed as ng of $\mathrm{N}$-acetyl glucosamine product produced $/ \mathrm{min} / \mathrm{g}$ fresh weight of kiwifruit flesh, with error bars indicating SEM. Some data points are missing from genotype 4C because fruit was too degraded to measure chitinase activity.

Actinidia chinensis genotype had a significant effect $(\mathrm{P}=0.0123)$ on $\mathrm{PAL}$ activity, with activity in genotype $4 \mathrm{C}$ and Hort16 A being greater than that in genotypes $8 \mathrm{~A}$ and 10B. In all selections, PAL activity increased significantly with storage and in infected versus non-infected fruit (Fig. 3). Inoculation treatment did not appear to affect PAL activity (Fig. 3).

\section{DISCUSSION}

Inoculating fruit pre-harvest with $C$. actinidiae did not markedly increase subsequent disease incidence compared with that in water-sprayed controls. This indicates that natural populations of this pathogen within A. chinensis are reasonably well established. Given its natural prevalence and the fact that $C$. actinidiae is one of the most important pathogens of Hort16A (Manning et al. 2003), coupled with observations in the current paper that levels of resistance to this pathogen vary in different $A$. chinensis genotypes, there is a need to include tests of $C$. actinidiae resistance into future A. chinensis breeding experiments.

Disease assessments of the $4 \mathrm{C}$ genotype were extremely difficult, because the tissue had completely collapsed and had become colonised by numerous opportunistic microbes. This also affected enzyme measurements, because it was almost impossible to distinguish soft rots from other rots and to sample any healthy tissue surrounding $C$. actinidiae lesions. The inability to store genotype 4C precludes it from further commercial development. 

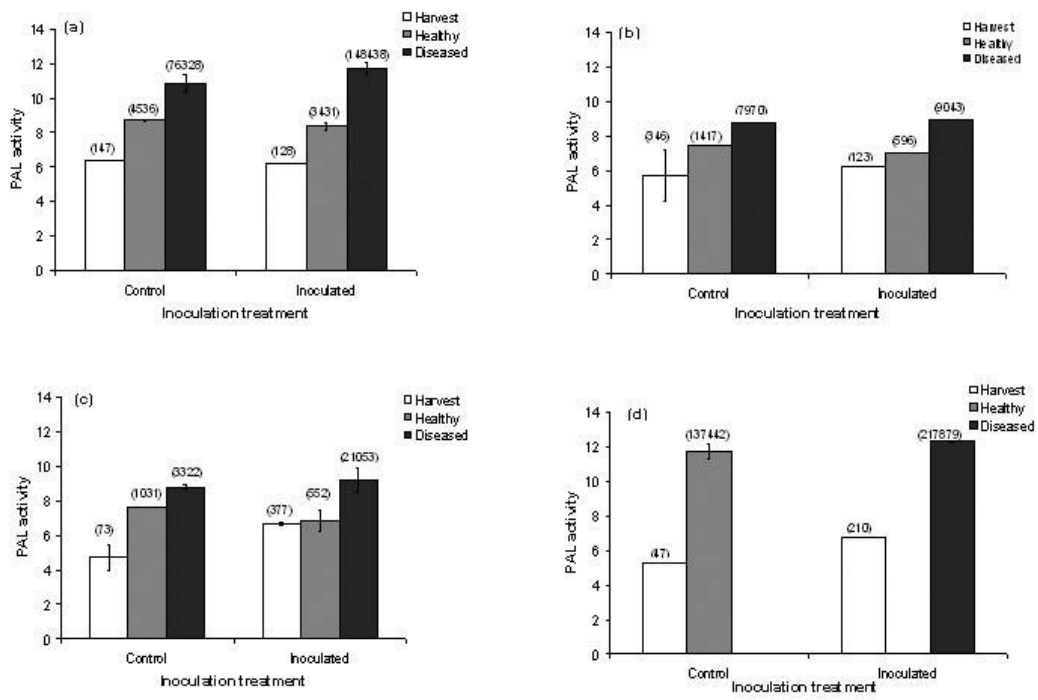

FIGURE 3: Phenylalanine ammonia lyase (PAL) activity in four Actinidia chinensis selections, (a) Hort16A, (b) 8A, (c) 10B and (d) 4C, as measured at harvest time, and after 18 weeks of storage at $1.5^{\circ} \mathrm{C}$ in healthy and diseased kiwifruit fruit tissue that had been inoculated pre-harvest with Cryptosporiopsis actinidiae or treated with water (control fruit). PAL activity is expressed as counts per minute $(\mathrm{CPM})$ of ${ }^{14} \mathrm{C}$-labelled cinnamic acid product produced/g dry weight of kiwifruit flesh, with error bars indicating SEM. Some data points are missing from genotype $4 \mathrm{C}$ because fruit was too degraded to measure PAL activity. Data are presented after $\log _{\mathrm{e}}$ transformation, with error bars indicating SEM, and untransformed means in parentheses.

Although results are very preliminary, with only 4 A. chinensis genotypes being examined, this study suggests a continuum of levels of soft rot resistance, which is a characteristic of quantitative resistance (Young 1996), rather than a discrete absence/ presence of rots. Quantitative resistance in kiwifruit has also been observed for other important pests (McKenna et al. 2006; Hill et al. 2007) and diseases (Reglinski et al. 2001; Wurms 2004). Use of general defence genes as predictors of host resistance is a valuable and often-used tool in developing breeding lines with durable quantitative resistance, where inheritance of traits cannot be linked to simple Mendelian ratios (Young 1996). Chitinase and PAL have been successfully used as markers of host resistance in crops as diverse as apple, rice, potato, bean and tobacco (Geffroy et al. 2000; Wulff et al. 2003; Liu et al. 2004; Abo-Elyousr et al. 2006; Ott et al. 2006). Although expression of chitinase activity has been correlated with A. deliciosa cv. Hayward kiwifruit resistance to Botrytis cinerea (Wurms 2005), chitinase activity does not appear to be a marker for resistance of $A$. chinensis against $C$. actinidiae infection. This conclusion is based on the observations that elevated chitinase activity during storage correlated with decreased resistance, and that the presence of infection did not stimulate chitinase activity. Genotype 8A had the least chitinase activity and the most soft rots, and there was no link between the level of chitinase expression and susceptibility to $C$. actinidiae in the other A. chinensis selections. 
PAL activity is also unsuitable as a resistance marker for this host/pathogen interaction. PAL activity increased significantly with cold storage whilst fruit became more susceptible, and there was no cause/effect relationship between PAL activity of the various selections and incidence of rots caused by $C$. actinidiae. There was no difference between inoculated and control treatments in terms of PAL activity, but this is not surprising as disease incidences were also similar in both treatments. However, C. actinidiae infection did stimulate significant PAL activity. One explanation for this might be that the PAL assay is measuring pathogen as well as kiwifruit PAL activity in infected tissue. It is known that the chitinase assay can distinguish plant and fungal chitinases provided that sampling is restricted to apparently healthy tissue surrounding disease lesions (Wurms et al. 1997), but it is not known whether this is the case for the PAL assay. Consequently, PAL induction by the pathogen does not constitute strong proof of its role in resistance, and would require verification by molecular assays.

In conclusion, a simple bioassay of resistance has not yet been found, but given the prevalence of this pathogen and the problem it poses the industry (Manning et al. 2003), further studies are merited.

\section{ACKNOWLEDGEMENTS}

We gratefully acknowledge the New Zealand Foundation for Research, Science and Technology for funding this research, carried out as part of the Reducing Fungicides contract C06X0302.

\section{REFERENCES}

Abo-Elyousr K, Yegen O, Zeller W 2006. Investigations on induced resistance against fire blight (Erwinia amylovora) with different bioagents. Proceedings of the 10th International Workshop on Fire Blight. Acta Horticulturae 704: 357-362.

Bernards MA, Ellis BE 1989. Phenylpropanoid metabolism in tomato cell cultures cocultivated with Verticillium alboatrum. Journal of Plant Physiology 135: 21-26.

Fullerton RA, Rheinländer PA, Manning MA, Casonato SG 2007. Infection and rot expression by Cryptosporiopsis actinidiae and Phomopsis sp. in kiwifruit, Actinidia chinensis 'Hort16A'. Proceedings of the 6th International Kiwifruit Symposium. Acta Horticulturae. In Press.

Geffroy V, Sévignac M, De Oliveira JCF, Fouilloux G, Skroch P, Thoquet P, Gepts P, Langin T, Dron M 2000. Inheritance of partial resistance against Colletotrichum lindemuthianum in Phaseolus vulgaris and co-localization of quantitative trait loci with genes involved in specific resistance. Molecular Plant Microbe Interactions 13: 287-296.

Hill MG, Mauchline NA, Cheng C-H, Connolly PG 2007. Measuring the resistance of Actinidia chinensis to armoured scale insects. Proceedings of the 6th International Kiwifruit Symposium. Acta Horticulturae. In Press.

Liu B, Zhang S, Zhu X, Yang Q, Wu S, Mei M, Mauleon R, Leach J, Mew T, Leung H 2004. Candidate defense genes as predictors of quantitative blast resistance in rice. Molecular Plant Microbe Interactions 17: 1146-1152.

Manning MA, Meier X, Olsen TL, Johnston PR 2003. Fungi associated with fruit rots of Actinidia chinensis 'Hort16A' in New Zealand. New Zealand Journal of Crop and Horticultural Science 31: 315-324.

McKenna CE, Dobson SJ, Connolly PG 2006. Techniques for detecting Actinidia resistance to leafrollers. New Zealand Plant Protection 59: 51-56.

Molano J, Durán A, Cabib E 1977. A rapid and sensitive assay for chitinase using tritiated chitin. Analytical Biochemistry 83: 648-656.

Ott PG, Varga GJ, Szatmári A, Bozsó Z, Klement E, Medzihradszky KF, Besenyei E, Czelleng A, Klement Z 2006. Novel extracellular chitinases rapidly and specifically induced by general bacteria elicitors and suppressed by virulent bacteria as a marker for early basal resistance in tobacco. Molecular Plant Microbe Interactions 19: 161-172. 
Reglinski TR, Whitaker G, Cooney JM, Taylor JT, Poole PR, Roberts PB, Kim KK 2001. Systemic acquired resistance to Sclerotinia sclerotium in kiwifruit vines. Physiological and Molecular Plant Pathology 58: 111-118.

Rheinländer PA, Fullerton RA, Manning MA, Casonato SG 2005. Infection and rot expression by Cryptosporiopsis actinidiae and Phomopsis sp. in kiwifruit, Actinidia chinensis var. Hort16A. Abstracts from the 15th Biennial Conference of the Australasian Plant Pathology Society, Geelong Australia, 26-29 September 2005. p. 69.

Wurms K, Long P, Greenwood D, Sharrock K, Ganesh S 1997. Endo- and exo-chitinase activity in kiwifruit infected with Botrytis cinerea. Journal of Phytopathology 145: 145-151.

Wurms KV 2004. The incidence of Botrytis cinerea and expression of putative host defences in green- and golden-fleshed kiwifruit of differing harvest maturity. New Zealand Plant Protection 57: 125-129.

Wurms KV 2005. Susceptibility to Botrytis cinerea, and curing-induced responses of lytic enzymes and phenolics in fruit of two kiwifruit (Actinidia) cultivars. New Zealand Journal of Crop and Horticultural Science 33:25-34.

Wulff EG, Gonzales EV, Ortega JA, Torres S, Perez W, Nelson R, Bonierbale M 2003. Comparative analysis of new sources of late blight resistance using phenotypic and molecular genetic approaches. Proceedings of the XXVI International Horticultural Convention on Potatoes - Healthy Food for Humanity. Acta Horticulturae 619: 23-29.

Young ND 1996. QTL mapping and quantitative disease resistance in plants. Annual Review of Phytopathology 34: 479-501. 